\title{
Review \\ Intra-Arterial Infusion Chemotherapy in Advanced Pancreatic Cancer: A Comprehensive Review
}

\author{
Carmelo Laface $^{1,2}$ D, Mariarita Laforgia ${ }^{3}$, Pasquale Molinari ${ }^{1}$, Caterina Foti ${ }^{4}$, Francesca Ambrogio ${ }^{4}$, \\ Cosmo Damiano Gadaleta ${ }^{1}$ and Girolamo Ranieri ${ }^{1, *}$
}

1 Interventional and Medical Oncology Unit, IRCCS Istituto Tumori “Giovanni Paolo II", Viale Orazio Flacco 65, 70124 Bari, Italy; c.laface@studenti.uniba.it (C.L.); p.molinari@oncologico.bari.it (P.M.); c.gadaleta@oncologico.bari.it (C.D.G.)

2 Department of Biomedical Sciences and Clinical Oncology, University of Bari Aldo Moro, 70124 Bari, Italy

3 Pharmacy Unit, IRCCS Istituto Tumori “Giovanni Paolo II", Viale Orazio Flacco 65, 70124 Bari, Italy; m.laforgia@oncologico.bari.it

4 Department of Biomedical Science and Human Oncology, Dermatological Clinic, University of Bari Aldo Moro, 70124 Bari, Italy; caterina.foti@uniba.it (C.F.); francesca.ambrogio@uniba.it (F.A.)

* Correspondence: g.ranieri@oncologico.bari.it

check for updates

Citation: Laface, C.; Laforgia, M.; Molinari, P.; Foti, C.; Ambrogio, F.; Gadaleta, C.D.; Ranieri, G. Intra-Arterial Infusion Chemotherapy in Advanced Pancreatic Cancer: A Comprehensive Review. Cancers 2022, 14, 450. https://doi.org/10.3390/ cancers14020450

Academic Editor: Atsushi Sofuni

Received: 5 December 2021

Accepted: 14 January 2022

Published: 17 January 2022

Publisher's Note: MDPI stays neutral with regard to jurisdictional claims in published maps and institutional affiliations.

Copyright: (C) 2022 by the authors. Licensee MDPI, Basel, Switzerland. This article is an open access article distributed under the terms and conditions of the Creative Commons Attribution (CC BY) license (https:// creativecommons.org/licenses/by/ $4.0 /)$.
Simple Summary: Pancreatic cancer has a very poor prognosis. The few available therapeutic options are characterized by low efficacy and high toxicity due to the intrinsic chemoresistance of this tumor type. To improve clinical results, some clinical trials have evaluated regional chemotherapy as a treatment option for PC. The pancreatic arterial infusion of chemotherapeutics has the aim of obtaining higher local concentrations of drugs and, at the same time, of limiting systemic toxicity. This therapeutic approach has already been successfully evaluated for the treatment of several types of tumors. Regarding advanced pancreatic cancers, only a few clinical studies have investigated the safety and efficacy of this treatment, with very promising results. Therefore, in this review, we summarize literature data on the clinical approaches to pancreatic arterial drug administration for the treatment of advanced PC to deepen knowledge on this topic.

\begin{abstract}
Advanced pancreatic cancer (PC) has a very poor prognosis due to its chemoresistant nature. Nowadays, only a few therapeutic options are available for PC, and the most effective ones are characterized by low response rates (RRs), short progression-free survival and overall survival, and severe toxicity. To improve clinical results, small series studies have evaluated loco-regional chemotherapy as a treatment option for PC, demonstrating its dose-dependent sensitivity towards the tumor. In fact, pancreatic arterial infusion (PAI) chemotherapy allows higher local concentrations of chemotherapeutic agents, sparing healthy tissues with a lower rate of adverse events compared to systemic chemotherapy. This therapeutic approach has already been evaluated in different types of tumors, especially in primary and metastatic liver cancers, with favourable results. With regard to advanced PC, a few clinical studies have investigated the safety and efficacy of PAI with promising results, especially in terms of RRs compared to systemic chemotherapy. However, clear evidence about its efficacy has not been established yet nor have the underlying mechanisms leading to its success. In this review, we aim to summarize the literature data on the clinical approaches to pancreatic arterial drug administration in terms of techniques, drug pharmacokinetics, and clinical outcomes for advanced PC.
\end{abstract}

Keywords: pancreatic cancer; intra-arterial infusion chemotherapy; implanted pump or port

\section{Introduction}

Pancreatic cancer (PC) is the fourth most common cause of cancer mortality, with a 5 -year survival rate of only $8 \%$, although it is considered a rare tumor [1-3]. Standard therapies are represented by radical surgery and adjuvant chemotherapy for the early stages, 
although $60-70 \%$ of patients present a relapse after 2 years [4]. Concerning metastatic setting, a randomized phase II-III French study published in 2011 evaluated 342 previously untreated advanced PC patients (age 18-75 years, ECOG 0-1) that were randomized to receive the FOLFIRINOX schedule (5-fluorouracil, folic acid, irinotecan, oxaliplatin) vs. gemcitabine [5]. The results showed $\mathrm{f}$ a significant advantage or the experimental group both in the median progression-free survival (mPFS) (6.4 months vs. 3.3 months; HR $0.47(0.37-0.59) ; p<0.0001)$ and in the median overall survival (mOS) (11.1 months vs. 6.8 months; HR $0.57(0.45-0.73) ; p=0.001)$. However, several Grade 3-4 adverse events (AEs) occurred in the experimental group patients: $23 \%$ experienced asthenia, 15\% experienced vomiting, $13 \%$ experienced diarrhoea, and $9 \%$ experienced peripheral neuropathy [5]. More recently, a phase III study evaluated 154 advanced PC patients with BRCA 1-2 germline mutation and without disease progression during the 4 months after first-line platinum-based chemotherapy to receive olaparib or placebo [6]. This clinical trial demonstrated that the mPFS was significantly longer in the olaparib group than it was in the control group (median 7.4 months versus 3.8 months, respectively) [6]. Gemcitabine plus nab-paclitaxel is another schedule for the treatment of fit and untreated advanced PC patients; a multicentre phase III study showed that this combination regimen is associated with a longer mPFS (median 5.5 months vs. 3.7 months; HR $0.69(0.62-0.83) ; p<0.0001)$ and OS (median 8.5 months vs. 6.7 months; HR $0.72(0.62-0.83) ; p<0.0001)$ compared to gemcitabine alone [7]. As a further development in these treatments, another recent schedule for fit patients is the quadruple combination therapy, called PAXG (cisplatin $30 \mathrm{mg} / \mathrm{m}^{2}$, nab-paclitaxel $150 \mathrm{mg} / \mathrm{m}^{2}$, and gemcitabine $800 \mathrm{mg} / \mathrm{m}^{2}$ on days 1 and 15 and oral capecitabine $1250 \mathrm{mg} / \mathrm{m}^{2}$ on days 1-28 every 4 weeks), including all drugs indicated in PC. PACT-19 is a randomised phase 2 trial comparing PAXG to the standard combination of nab-paclitaxel and gemcitabine. At 6 months, 74\% of the participants in the experimental group were alive and free from disease progression compared to $46 \%$ of the patients in the control group [8].

PC generally has a very poor prognosis because only a few therapeutic options are available; moreover, it has low efficacy and high toxicity [9-11].

The former is due to the drug resistance of PC, which mainly depends on the simultaneous presence of a mechanical and a biological barrier [12]. The first is represented by a very dense, poorly vascularized, fibrotic, almost drug-impenetrable envelope surrounding pancreatic tumor area [13-17] even though the pancreas itself has a poor vascularization. This condition hampers the systemic chemotherapeutic agents to reach the pancreas and, therefore, the tumor cells in a sufficient amount to be effective [13]. The second impediment derives from the high expression of the cells comprising the multidrug resistance gene (MDR1) product, the membrane-bound P-170 glycoprotein [18]. It is a part of an ATPdependent drug efflux enzyme system that is able to quickly eliminate chemotherapeutic drugs from tumor cells [18]. In this regard, non-randomized, small series studies have demonstrated that PC has a dose-dependent sensitivity to regional chemotherapy [19-22]. In fact, it is expected that the drug dose that is delivered to the pancreatic tumor site must be at least five-fold higher to overcome the tumor cell resistance due to the P-170 glycoprotein [23].

In summary, the poor prognosis, the limited treatment strategies, and the anatomical and biological features of PC justify the medical need for new therapeutic options. One recent promising route is the application of loco-regional therapies, particularly the pancreatic arterial infusion (PAI) of chemotherapy, delivering remarkably higher concentrations of antineoplastic agents to the tumor site than systemic administration and limiting adverse events (AEs).This type of therapeutic approach has already been successfully evaluated in various solid tumors, specifically in primary and metastatic liver cancers [24-36]. As for advanced PC, only a few clinical trials have investigated the safety and efficacy of PAI with promising results, especially in terms of high response rates (RRs) compared to systemic chemotherapy [23]. However, clear evidence about its efficacy has not been established yet nor have the biological mechanisms underlying clinical response. 
In this review, we aim to summarize the literature data on the therapeutic approaches to the pancreatic arterial administration of chemotherapy in terms of techniques, drug pharmacokinetics, clinical studies, and clinical results for advanced PC.

\section{Pancreatic Arterial Infusion of Chemotherapy}

\subsection{Technical Procedure}

The pancreas is characterized by an extremely variable vascular anatomy and is supplied by several vessels [37]. Specifically, pancreatic parenchyma is vascularized by two main vessels: the celiac artery and the superior mesenteric artery (SMA) [38]. The first feeds the pancreatica magna, dorsal pancreatic, and caudal pancreatic arteries, supplying the pancreatic body and tail [38-40]. On the other hand, the pancreatic head is supplied by the pancreaticoduodenal arcade that derives from the junction of the anterosuperior pancreaticoduodenal and the postero-superior-pancreatico-duodenal arteries that originate from the gastroduodenal and the inferior pancreaticoduodenal ones that arise from the SMA [38] (Figure 1A,B).
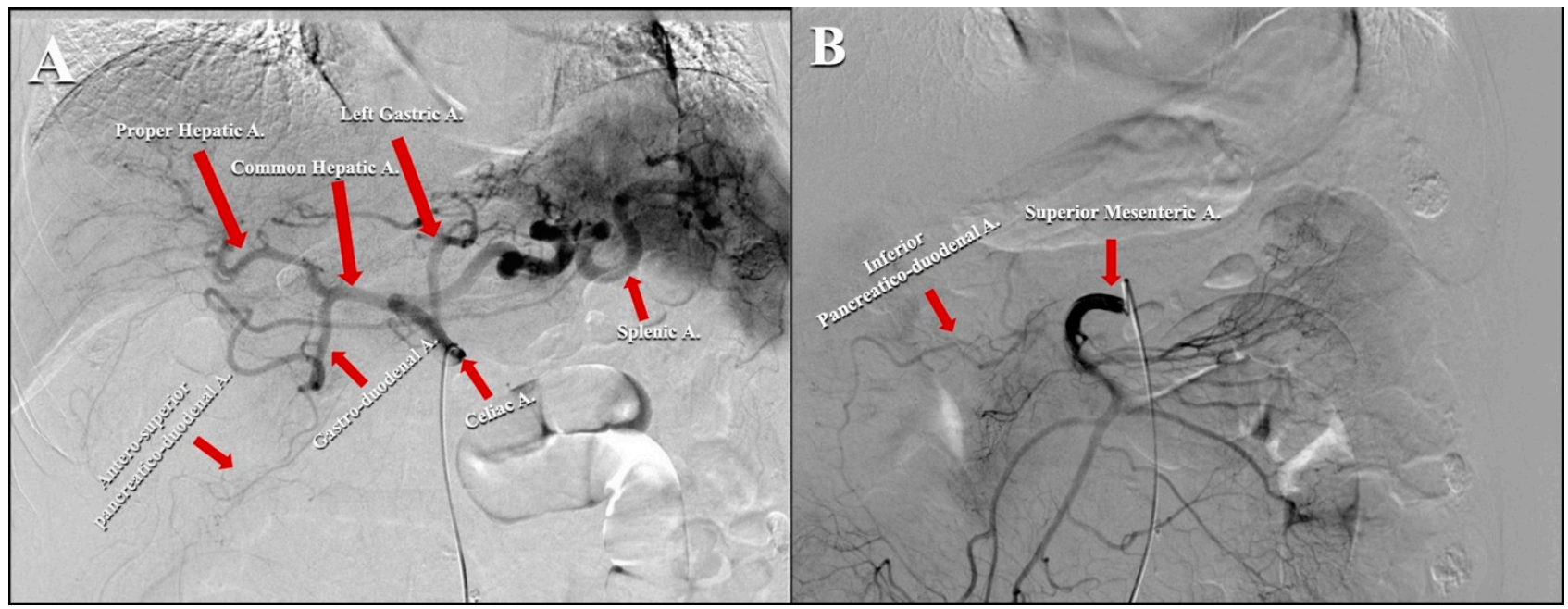

Figure 1. (A) Angiographic scan representing the vascular anatomy of celiac artery. (B) Angiographic scan representing vascular anatomy of superior mesenteric artery.

This peculiar anatomy makes the catheter placement site one of the main issues in PAI chemotherapy. The first studies reported PAI through both the celiac artery and SMA to cover all pancreatic cancer areas [41]. For this reason, PAI chemotherapy is considered to be a difficult challenge due to the complicated management of dual arterial infusion. Moreover, a pilot clinical study of arterial drug infusion via the SMA in the context of dual PAI for advanced PC reported gastrointestinal toxicity, such as hypoalbuminemia and diarrhoea [42].

Subsequent studies have described a new technique that consists of the unification of the two pancreatic vascular networks [43,44]. In this way, a single arterial infusion of chemotherapeutic drugs via the celiac artery has been achieved with a sufficient antitumor effect and without the AEs deriving from chemotherapeutic administration via the SMA. To be specific, this approach involves the embolization of all pancreatic arteries originating from the SMA to grant a single supply from the celiac artery. Concerning the arterial infusion technique, the first step consists of an angiographic examination using a 5.5-French angiographic catheter through both the celiac artery and SMA to evaluate pancreatic vascular anatomy. In the next step, a microcatheter is inserted into the pancreatic arteries arising from SMA: the anteroinferior pancreaticoduodenal and the posteroinferior pancreaticoduodenal arteries and their subsequent embolization employing microcoils. Sometimes, the dorsal pancreatic artery born from the SMA or inferior pancreaticoduodenal and the middle colic ones are also embolized. The embolization of the left and right gastric arteries 
and the right gastroepiploic artery is also performed to avoid the perfusion of the stomach and to increase the drug supply to the tumor. At this point, a 5-French catheter with a side hole is inserted through the femoral artery. For tumors of the pancreatic body or tail, the catheter tip is positioned into the hepatic artery with the side hole placed in the celiac artery to increase blood flow to the splenic artery. In the cases of tumors of the pancreatic head, the catheter tip is placed into the splenic artery, with the side hole in the celiac artery to increase flow to the gastroduodenal artery. Subsequently, the splenic artery is embolized with coils, and the infusion catheter is fixed. If the dorsal pancreatic artery arises from the splenic artery, the coils are inserted at the distal tract of dorsal pancreatic artery, allowing PAI into both the dorsal pancreatic and the gastroduodenal arteries. Moreover, in this way, the whole liver is successfully supplied by the celiac artery; this is a very useful strategy because the liver is the most frequent site for distant metastases in PC patients. Finally, the catheter's proximal end is connected to a subcutaneous implantable port. CT angiographic scans are performed using the arterial infusion of the contrast medium through the implanted port. The procedure is considered successful when the whole tumor area is enhanced after the injection of the contrast medium through the celiac arterial and after the blood supply from the SMA disappears [41] (Figure 2).

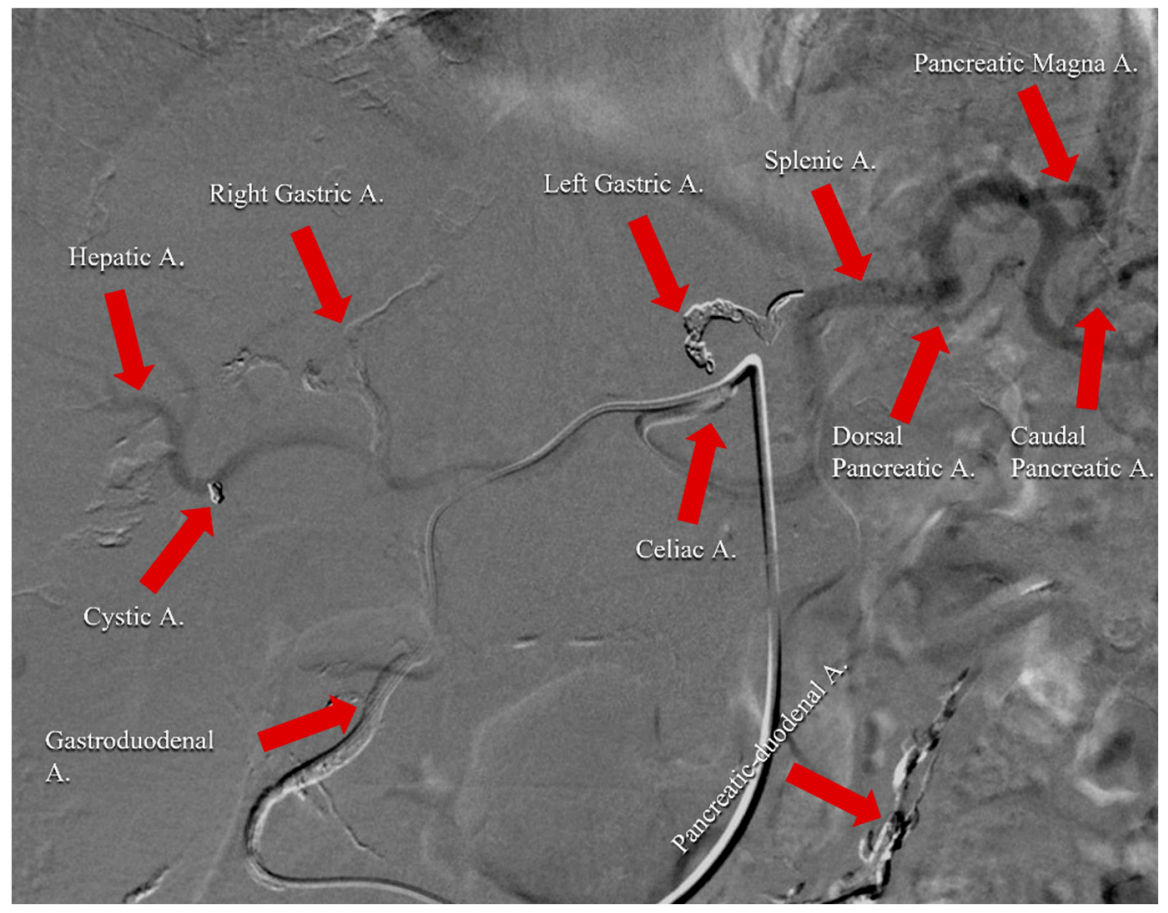

Figure 2. Angiographic scan following injection of contrast medium through celiac arterial after the completion of the technical procedure. It represents an example of the vascular remodulation of the celiac trunk for a patient affected by pancreatic cancer with liver metastases. Right gastric, left gastric, gastroduodenal, cystic, and pancreatic-duodenal arteries were embolized with spirals and coils to avoid perfusion of the stomach, duodenum, and gallbladder. Infusion catheter was fixed into gastroduodenal artery.

However, in spite of these great advances in techniques, PC often invades the surrounding organs, and new networks of blood vessels are formed accordingly. Therefore, the unification of the pancreatic blood supply might also be complex in some cases because of the site and area of tumor invasion [43]. 


\subsection{Pharmacokinetic Evaluation}

The current knowledge about the pharmacokinetic data for PAI infusion is very poor. Only a few studies have tried to evaluate the advantage of PAI chemotherapy in terms of kinetics, but most of them concern animal model experiments.

Gemcitabine is one of the most used drugs in the treatment of advanced PC [45]. From a pharmacological point of view, it is a pyrimidine analogue that needs to be activated in the cells by the deoxycytidine kinase $(\mathrm{dCK})$ enzyme in difluorodeoxycitidin-diphosphate and triphosphate [46]. Gemcitabine acts by altering the correct DNA synthesis through the inhibition of the ribonucleotide reductase enzyme [45]. Literature data have demonstrated that high levels of $\mathrm{dCK}$ are present in different human tumoral cells; therefore, PAI chemotherapy might significantly spare healthy tissues. The half-life of gemcitabine is 42-92 min after intravenous administration, but its pharmacokinetic properties have also been tested after hepatic arterial infusion (HAI), with interesting results in terms of liver extraction rates [47]. A study has investigated the feasibility of PAI with gemcitabine for the treatment of 10 Beagle dogs affected by locally advanced PC. The authors evaluated the drug concentration in blood and various tissue samples after the administration of the same dosage of gemcitabine $(45 \mathrm{mg} / \mathrm{kg}$ ) both through PAI via the celiac axis and SMA and intravenous infusion. The results demonstrated that PAI with gemcitabine is feasible and might significantly increase the drug concentration in serum and in the pancreatic tumor area, prolonging drug retention in the animal body with respect to intravenous infusion [48].

The compound 5-fluorouracil (5-FU) blocks both the conversion of cytosine nucleosides into the deoxy-derivatives and the incorporation of the thymidine nucleotide into the DNA strand [49]. The half-life of 5-FU is $8-20 \mathrm{~min}$; therefore, its principal administration route is via continuous infusion (c.i.). Moreover, the infusion of an initial bolus allows the therapeutic window to be reached more rapidly, which is then sustained by the subsequent c.i. Literature data have already evaluated the 5-FU liver extraction rate after HAI, which is approximately 75-80\% [24], and several clinical trials have demonstrated remarkable efficacy in the treatment of primary and secondary hepatic malignancies. Tao et al. tested the pharmacokinetic differences between PAI and the intravenous infusion of 5-FU in a Wistar rat model. In this study, the authors demonstrated that the maximum concentration of 5-FU in the pancreas as well as the clearance time of the pancreas were significantly higher in the population treated with PAI 5-FU $(20.00 \mathrm{mg} / \mathrm{g}$ and $90 \mathrm{~min}$ for PAI versus $8.42 \mathrm{mg} / \mathrm{g}$ and $50 \mathrm{~min}$ for intravenous infusion) [50]. Other experimental studies employing dog and pig models of advanced PC confirmed that PAI 5-FU allows a higher drug concentration in PC without inducing toxicity on the healthy pancreatic tissues, the duodenum, and the liver compared to intravenous administration [44,51].

Platinum salts are alkylating agents that act on the N7 guanines along the DNA double strand. Intra-arterial hepatic versus the intravenous administration of cisplatin or oxaliplatin in a VX2 tumor model in White New Zealand female rabbits was performed (cisplatin $4 \mathrm{mg} / \mathrm{kg}$ or oxaliplatin $6 \mathrm{mg} / \mathrm{kg}$ ). Atomic absorption spectrometry measured the platinum concentration at different times. The results demonstrated that oxaliplatin has better pharmacokinetic parameters and a more major tissue concentration via HAI than ev administration; for cisplatin, no differences in the pharmacokinetic parameters or platinum tissue accumulation were reported. No PAI kinetic studies in animals have been found in literature for platinum salts [52].

Only one study evaluated the pharmacokinetic parameters of PAI chemotherapy in a human population. To be specific, Kakizaki et al. enrolled four patients with advanced PC who underwent PAI Cisplatin with angiotensin II through an implantable drug delivery system. The authors showed that the drug concentration was 1.3 times higher in the PC tissue than it was in the adjacent normal tissue [53]. 


\section{Clinical Trials}

\subsection{Published Reports}

In the literature, only a few clinical trials have evaluated the role of PAI chemotherapy for advanced PC patients (UICC stage III or IV for liver metastases). This review investigates the safety concerning AEs and the efficacy in terms of the disease control rate (DCR), objective response rate (ORR), $\mathrm{mPFS}$, and $\mathrm{mOS}$ of this type of loco-regional therapy. We have reported and summarized (Table 1) all of the clinical trials that have been performed.

Table 1. Compilation of references included in the review of the literature that evaluated PAI chemotherapy in advanced PC patients.

\begin{tabular}{|c|c|c|c|c|c|c|}
\hline References & Type of Study & PAI Chemotherapy & $\begin{array}{c}\text { Systemic } \\
\text { Chemotherapy }\end{array}$ & $\mathrm{DCR} / \mathrm{RR} *(\%)$ & $\begin{array}{l}\text { mPFS } \\
(\mathrm{mo} .)\end{array}$ & mOS (mo.) \\
\hline Cantore et al. [54] & Phase II & FLEC & No & $59 / 15^{*}$ & n.e. & 9.9 \\
\hline Homma et al. [55] & Phase II & 5-FU, cisplatin & No & $73.9 *$ & n.e. & $18.26 \pm 10 * *$ \\
\hline Cantore et al. [56] & Phase III & FLEC (experimental group) & $\begin{array}{l}\text { Gemcitabine } \\
\text { (control group) }\end{array}$ & $\begin{array}{l}50 \text { vs. } 46^{\mathrm{np}} / 14^{*} \\
\text { vs. } 5.9^{\mathrm{np}}\end{array}$ & n.e. & 7.9 vs. $5.8^{p}$ \\
\hline Aigner et al. [57] & Phase II & $\begin{array}{c}\text { Mitomycin, } \\
\text { mitoxantrone, cisplatin }\end{array}$ & No & n.e. & n.e. & 9 \\
\hline Mambrini et al. [58] & Phase II & FLEC & No & $58.3 / 7.6^{*}$ & n.e. & 9.2 \\
\hline Ishikawa et al. [59] & Phase II & Gemcitabine, 5-FU, cisplatin & No & $50 *$ & n.e. & 12 \\
\hline Tanaka et al. [42] & Pilot & 5-FU, radiotherapy & No & $70 *$ & n.e. & 11 \\
\hline Miyanishi et al. [60] & Phase I & Gemcitabine, 5-FU & No & $33.3^{*}$ & n.e. & 22.7 \\
\hline Sasada et al. [61] & Phase II & 5-FU, cisplatin & No & $58.3^{*}$ & n.e. & 22 \\
\hline Tanaka et al. [62] & Phase I/II & Gemcitabine, 5-FU & No & $68.8 *$ & 6 & 9.8 \\
\hline Liu et al. [63] & Meta-analysis & Different regimens & $\begin{array}{l}\text { Yes (control } \\
\text { groups) }\end{array}$ & 58.06 vs. $29.37 \mathrm{p}$ & n.e. & $5-21$ vs. $2.7-14^{\mathrm{p}}$ \\
\hline Chen et al. [64] & Phase II & Gemcitabine, oxaliplatin & No & 65.6 & n.e. & 10 \\
\hline Liu et al. [65] & Retrospective & Gemcitabine, oxaliplatin & No & n.e. & n.e. & 7 \\
\hline Qiu et al. [66] & Retrospective & No data & No & 62.6 & n.e. & 4.9 \\
\hline Ikeda et al. [67] & Phase II & 5-FU & Gemcitabine & $45^{*}$ & n.e. & $8.8 \pm 1.5^{* *}$ \\
\hline Heinrich et al. [68] & Phase II & Mitomycin, gemcitabine & Gemcitabine & $25^{*}$ & n.e. & 9.1 \\
\hline Uwagawa et al. [69] & Phase II & Nafamostat mesilate & Gemcitabine & $88.6 / 17^{*}$ & n.e. & 10 \\
\hline Barletta et al. [70] & Phase II & FLEC & No & $58.8 / 21.9 *$ & n.e. & 11.8 \\
\hline
\end{tabular}

\subsubsection{PAI as First Line Treatment without Systemic Chemotherapy}

In 2000, Cantore et al. [54] showed the clinical outcomes for 96 never treated PC patients (48 with UICC stage III and 50 with UICC stage IV) who underwent a PAI with FLEC regimen every 3 weeks for 3 cycles (5-FU $1000 \mathrm{mg} / \mathrm{m}^{2}$, folinic acid $100 \mathrm{mg} / \mathrm{m}^{2}$, epirubicin $60 \mathrm{mg} / \mathrm{m}^{2}$, carboplatin $300 \mathrm{mg} / \mathrm{m}^{2}$ ) in a phase II clinical trial. From a pharmaceutical point of view, the choice of carboplatin with respect to cisplatin was strategically linked to its major solubility in an aqueous solution, translating into a higher drug dosage with a smaller administration volume. Each cycle was performed using an angiographic catheter that was placed into the gastroduodenal artery for pancreatic head tumors, into the splenic artery for pancreatic body and tail ones, and into the hepatic artery when liver metastases were present (50/96 patients), allowing half of the total dose was infused to the liver. When this technical approach was not possible, the chemotherapeutics were administered into the celiac axis. The authors reported an ORR of $15 \%$, a DCR of $59 \%$, and a mOS of 9.9 months (10.6 and 6.8 for stage III and IV, respectively). As far as toxicity was concerned, $25 \%$ of the patients experienced grade $3-4$ hematologic and 3\% experienced gastrointestinal AEs. 
Only one patient experienced a technique-related complication that consisted of an intimal dissection of the iliac artery.

In 2000, Homma et al. [55] analyzed PAI chemotherapy in 23 metastatic PC patients by means of an infusion catheter placed into the splenic artery for the treatment of primary PC as well as into the common hepatic artery for those patients with liver metastases in a phase II study. In the first cases, $5-\mathrm{FU}\left(250 \mathrm{mg} / \mathrm{m}^{2}\right.$ in $24 \mathrm{~h}$ c.i. for 7 days $)$ and cisplatin $\left(10 \mathrm{mg} / \mathrm{m}^{2}\right.$ on Days 1, 3 and 5) administration was performed at weeks 1 and 3, within a course of 28 days. In the second cases, the same dosage of 5-FU was administered to both the primary tumor and metastatic lesions. The ORR was $73.9 \%$, while the mean OS was 19 months. The ORR was $68.8 \%$ in the group of patients with liver metastases (16 patients), while the mean OS was $16.25 \pm 8.35$ months. About $20 \%$ of the patients experienced technique-related complications, such as dislocation of the catheter tip, arterial obstruction, and abscess in the femoral region, while no grade 3-4 AEs occurred.

In 2004, Cantore et al. [56] compared standard intravenous gemcitabine (32 with stage III and 35 with stage IV patients) with a PAI FLEC schedule (35 with stage III and 36 with stage IV patients) using an angiographic catheter placed into the celiac axis in a multicenter, open, randomized phase III clinical trial. Patients in the control group were administered $1000 \mathrm{mg} / \mathrm{m}^{2}$ in $30 \mathrm{~min}$ intravenous infusion every week a total of seven consecutive times followed by 1 week of rest and then received intravenous infusion weekly for 3 weeks every month. The ORR was $14 \%$ versus $5.9 \%$ in the FLEC and gemcitabine groups (no statistical difference), respectively, while the $\mathrm{mOS}$ was significantly longer in the experimental group $(7.9$ months versus 5.8 months $(p=0.036))$. A total of $22.4 \%$ of patients in the gemcitabine group and $47.9 \%$ of the patients in the experimental group experienced at least one grade 3-4 AE.

In 2005, Aigner et al. [57] evaluated PAI via the celiac axis or common hepatic artery with fixed dose boli of mitomycin (10-15 mg), mitoxantrone (10 mg), and cisplatin (50 mg) adsorbed on degradable starch microspheres ( $3 \mathrm{~mL}$; Spherex) for five cycles followed by one course of isolated hypoxic abdominal perfusion with mitomycin $(30 \mathrm{mg})$ and cisplatin $(70 \mathrm{mg}$ ) to prevent or treat potential peritoneal carcinosis in a phase II study involving 265 patients (112 with UICC stage III and 153 with IV). The mOS was 9 months, and the resecability rate for long-term survivors (>12 months) after treatment was 39\%. No severe toxicity was reported.

In 2006, Mambrini et al. [58] tested a PAI FLEC regimen once more via the celiac axis in 211 patients (99 patients with UICC stage III and 112 with IV). The ORR, DCR, and $\mathrm{mOS}$ were $7.6 \%, 58.3 \%$, and 9.2 months, respectively. No angiographic procedurerelated complications were observed, although three intimal dissections of the iliac artery were reported. Among patients, $24 \%$ and 3\% experienced Grade 3-4 hematological and gastrointestinal AEs, respectively; moreover, grade 3 alopecia was reported in $15 \%$ of the participants.

In 2007, Ishikawa et al. [59] conducted a clinical trial in 20 metastatic PC patients, testing PAI of gemcitabine, 5-FU, and cisplatin mixed together with angiotensin-II (AT-II). The aim was to increase the blood flow towards tumor areas while sparing healthy tissue. AT-II is one of the most powerful vasoconstrictors and is able to restrict blood flow in favor of liver perfusion during short (3-4 min) intra-arterial administrations. The ORR was 50\%, while the mOS was 1 year. No severe AEs were reported.

In 2007, Tanaka et al. [42] tested the pancreatic arterial c.i. of 5-FU $\left(333 \mathrm{mg} / \mathrm{m}^{2}\right.$ on days 1-5 a week for 5 weeks) in association with radiotherapy (50 Gy at 2.0 Gy per fraction) in 20 patients (10 with UICC stage III and 10 with IV) in a pilot study. PAI was performed using one or two catheters placed into the pancreatic arteries according to angiographical evaluation. The ORR and mOS were $70 \% \mathrm{~s}$ and 11 months, respectively. Among the patients, 55\% experienced severe non-hematological AEs, such as nausea and vomiting, diarrhoea, and hypoalbuminemia.

In 2008, Miyanishi et al. [60] investigated PAI gemcitabine $\left(600,800,1000 \mathrm{mg} / \mathrm{m}^{2}\right.$ on days 1 and 15 in three different cohorts) combined with the c.i. of $5-\mathrm{FU}\left(300 \mathrm{mg} / \mathrm{m}^{2}\right.$ on 
days 1-5 and 15-19 every 2 weeks) in 12 metastatic PC patients in a phase I clinical trial. All of the patients underwent super selective arterial embolization to alter the distribution of the blood flow into the pancreatic area, particularly through the larger pancreatic and the caudal pancreatic arteries. The ORR was $33.3 \%$, while the mOS was 22.7 months. No severe toxicity was encountered.

In 2008, Sasada et al. [61] evaluated the PAI 5-FU (c.i. of $250 \mathrm{mg} / \mathrm{m}^{2} /$ day for 7 days) and bolus infusion of cisplatin $\left(5 \mathrm{mg} / \mathrm{m}^{2} /\right.$ day for 5 days) in 16 advanced PC patients in a phase II clinical study. The catheter was placed to allow the perfusion of both the pancreatic tumor and the liver. For the 12 patients with Stage Iva disease, the ORR was 58.3\%, and the mOS was 22 months, while for the 4 patients with Stage IVb PC, the ORR was $0 \%$. Hematologic and hepatic AEs were the most common toxicities, causing two patients to discontinue treatment.

In 2012, Tanaka et al. [62] enrolled 20 patients (2 patients with UICC stage III and 18 with IV) in a phase I/II study to analyze the efficacy and safety of PAI gemcitabine $\left(1000 \mathrm{mg} / \mathrm{m}^{2}\right)$ and 5-FU (increasing dose from 750 to $\left.1000 \mathrm{mg} / \mathrm{m}^{2}\right)$. Arterial perfusion was performed via the celiac artery after embolization of the pancreatic arteries originating from the SMA. The ORR, mOS, and PFS were $68.8 \%, 9.8$ months, and 6 months, respectively. No technique-related complications and no severe AEs were reported, even when the dose of 5-FU was increased. The grade 3 side effects were neutropenia $(15.8 \%)$ and thrombocytopenia (5.3\%).

Published in 2012, a meta-analysis of six randomized controlled trials [63] evaluated the efficacy and safety of different PAI chemotherapy regimens compared to systemic treatments for advanced PC. This paper highlighted that PAI chemotherapy is more effective and has a lower risk of AEs than systemic chemotherapy. In detail, the ORR was higher in the PAI group ( $R R=1.99,95 \%$ CI: $1.50,2.65 ; 58.06 \%$ versus $29.37 \%$ ), as was the $\mathrm{mOS}$ (5-21 months versus 2.7-14 months). With regard to toxicity, AEs occurred in a lower percentage in the PAI group ( $R R=0.72,95 \%$ CI: $0.60,0.87 ; 49.03 \%$ versus $71.33 \%$ in the systemic treatment group).

In 2014, Chen et al. [64] evaluated the safety and efficacy of PAI in a phase II study via an angiographic catheter placed into the arteries providing blood to the tumor with gemcitabine $\left(1000 \mathrm{mg} / \mathrm{m}^{2}\right)$ and oxaliplatin $\left(100 \mathrm{mg} / \mathrm{m}^{2}\right)$ every 4 weeks in 32 locally advanced PC patients. The ORR was $25 \%$, the DCR was $65.6 \%$, and the mOS was 10 months. No PAI-related side effects were observed; grade 3-4 gastrointestinal AEs occurred in $21.9 \%$ of patients.

In 2016, Liu et al. [65] retrospectively tested gemcitabine-based PAI chemotherapy (gemcitabine $1000 \mathrm{mg} / \mathrm{m}^{2}$ and oxaliplatin $100 \mathrm{mg} / \mathrm{m}^{2}$ ) in 354 patients (187 patients with UICC stage III and 87 with IV disease) using an angiographic catheter via the celiac artery and SMA. The mOS was 7 months, and no data about toxicity were reported.

In 2019, Qiu et al. [66] showed the clinical results of a retrospective evaluation of PAI chemotherapy in 115 patients (12 with stage II disease, 31 with stage III disease, and 72 with stage IV disease). The ORR was $5.2 \%$, and the DCR was $62.6 \%$, while the mOS was 4.9 months. These endpoints were significantly higher in patients with an ECOG score $\leq 1$ and in those patients who received $>1$ sessions of PAI. Cerebral infarction, a sever AE, was reported after the technical procedure $(0.9 \%)$. No other severe complications were reported.

\subsubsection{PAI as First Line Treatment with Systemic Chemotherapy}

In 2006, Ikeda et al. [67] evaluated clinical results of combining PAI 5-FU (250 mg/day on days 1-5 every week in c.i.) with systemic gemcitabine (every week for 3 consecutive times) in 17 metastatic PC patients. An angiographic catheter was inserted into the celiac axis for allowing the chemotherapeutic perfusion of both the pancreatic tumor and the whole liver. The pancreatic arteries were super selectively embolized, excluding only the pancreatica magna and caudal pancreatic arteries flowing into the pancreatic parenchyma. The gastric and peripancreatic arteries were embolized by employing microcoils to prevent gastroduodenal toxicity due to the anticancer drugs. The ORR was $35 \%$ and $55 \%$ for the 
primary tumor site and liver metastases, respectively. The mean OS was $8.8 \pm 1.5$ months. No angiographic procedure-related AEs were documented. The most frequent side effects were hematologic alterations. Grade 3-4 non-hematologic AEs were observed in 23.5\% of the patients, such as cholangitis, mild cerebral infarction, duodenal ulcer, and partial splenic embolization.

In 2013, Heinrich et al. [68] conducted a phase II trial testing a PAI combination (mitomycin C $8.5 \mathrm{mg} / \mathrm{m}^{2}$ and gemcitabine $500 \mathrm{mg} / \mathrm{m}^{2}$ on days 1 and 22) by inserting an angiographic catheter into the celiac artery with the systemic administration of gemcitabine monotherapy (500 mg/m² on days 8 and 15) in 17 advanced PC patients. The ORR and mOS were $25 \%$ and 9.1 months, respectively. No procedure-related complications were reported. Hematological AEs were the most frequent ones, with 18 episodes of grade 3-4.

In 2013, Uwagawa et al. [69] reported the clinical outcomes of 35 PC patients (10 patients with UICC stage III and 20 with IV) who underwent PAI with Nafamostat Mesilate (4.8 mg/ $\mathrm{kg}$ in c.i.) and systemic gemcitabine $\left(1000 \mathrm{mg} / \mathrm{m}^{2}\right.$ intravenously) on Days 1,8 and 15 every 4 weeks in a phase II study. The mOS was 10.0 months, the ORR was $17.1 \%$, and DCR was $88.6 \%$. No technique-related complications were reported. Grade 3-4 hematological AEs were observed in $17 \%$ of patients.

\subsubsection{PAI as Second Line Treatment}

In 2006, Barletta et al. [70] analyzed a PAI FLEC regimen as second-line treatment in 32 patients (7 with UICC stage III and 25 with IV) in a phase II clinical trial. The ORR was $21.9 \%$, DCR was $58.8 \%$, and mOS was 11.8 months from diagnosis. Treatment was not discontinued due to toxicity in any case.

\subsection{Ongoing Clinical Trials}

Recently, only a few clinical trials have been designed to better define the role of PAI chemotherapy in the treatment of advanced PC.

NCT02635971 is one of the most interesting ongoing clinical trials. It is an open label, randomized, double-arm, prospective phase II study to check the efficacy and safety of PAI versus intravenous infusion with gemcitabine plus oxaliplatin every 2 weeks, with 168 unresectable PC patients currently being enrolled.

Furthermore, NCT01665625 is an open label, randomized, double-arm, prospective clinical trial designed to check the safety and efficacy of PAI chemotherapy using an implanted percutaneous left subclavian artery port-catheter drug delivery system compared to systemic treatment in an estimated 90 estimated who are affected by advanced PC.

Finally, NCT03257033 is an open label, randomized, double-arm, prospective phase III study. All of the enrolled patients will receive intravenous nab-paclitaxel $\left(125 \mathrm{mg} / \mathrm{m}^{2}\right.$ over $30 \mathrm{~min})$ and gemcitabine $\left(1000 \mathrm{mg} / \mathrm{m}^{2}\right.$ over $\left.30 \mathrm{~min}\right)$ on days 1,8 , and 15 over he course of 4 weeks and radiation therapy for 4 months. Subsequently, patients will be randomized to receive PAI gemcitabine (1000 $\mathrm{mg} / \mathrm{m}^{2}$ every week up to 8 administrations) using an intra-arterial catheter or to continue systemic chemotherapy for up to 16 weeks or until progression. Then, all of the subjects will receive systemic gemcitabine plus nab-paclitaxel or capecitabine.

\section{General Conclusions and Future Perspectives}

PC patients have a very poor prognosis due to the intrinsic chemoresistance of this type of tumor depending on: (a) the presence of a very dense, poorly vascularized, fibrotic envelope that involves pancreatic tumor area [13], (b) the poor vascularization of the pancreas, or (c) the high expression of the membrane-bound P-170 glycoprotein [18]. On the one hand, these factors hamper the systemic chemotherapeutic agents from reaching tumor cells in a sufficient enough amount to be effective and, on the other hand, the ATP-dependent drug efflux enzyme system quickly eliminates chemotherapeutic drugs from tumor cells, so standard therapeutic pharmacological options have limited success in PC [18]. 
Nowadays, a few therapeutic options are available for the treatment of PC that result in low RRs, short mPFS and mOS, and a high rate of severe side effects. The most effective treatment that is currently available for advanced PC is the FOLFIRINOX regimen [5]. This chemotherapeutic schedule has been proven to be more effective with respect to gemcitabine, though it led to an ORR of only $31.6 \%$ and an improvement in life expectancy of only 5 months with respect to gemcitabine [5]. In the $35 \%$ of PC patients who are affected by unresectable locally advanced disease at diagnosis [71], several clinical studies have demonstrated that FOLFIRINOX allows a resecability rate of about $26 \%$ to be obtained, and only $78 \%$ of patients receive an $\mathrm{R} 0$ resection [71,72]. It should be emphasized that all of these poor results have been obtained at the expense of a high rate of severe AEs, such as asthenia, vomiting, diarrhoea, peripheral neuropathy, and pancytopenia $[5,71,73]$.

With regard to PAI chemotherapy, pharmacokinetic data have been evaluated in small series studies on animals and human beings, demonstrating the dose-dependent sensitivity of pancreatic tumor cells to this loco-regional treatment. In detail, the direct infusion of different chemotherapeutic agents such as gemcitabine and 5-fluorouracil to the tumor site allows for these drugs to achieve higher local concentrations while sparing healthy tissues $[44,48,51]$.

On these bases, several clinical trials have tried to investigate PAI chemotherapy for unresectable locally advanced and metastatic PC with the aim of improving efficacy while limiting systemic toxicity.

To the best of our knowledge, most of the clinical studies reported in the scientific literature are phase II, with a single phase III study being available. The enrolled patient populations are affected by unresectable locally advanced and metastatic PC for liver involvement, and these subgroups are not distinguished in terms of clinical outcomes. Therefore, it is impossible to assess the effectiveness of the chosen experimental treatment for each clinical stage. Almost of all of the reported studies are characterized by a small patient population; for example, the phase III study only enrolled 138 patients, resulting in a subsequently low statistical weight. Furthermore, the administered chemotherapeutic agents are obsolete with respect to more recent treatments for PC. None of the reported trials evaluated either the current more effective treatments through PAI or a comparison with standard systemic therapy, except for the one phase III study. Finally, although it has been clarified that PC is a systemic disease since its inception [72], very few studies have been conducted to determine the combination of systemic treatment and PAI chemotherapy. The same studies did not compare this therapeutic strategy with standard chemotherapeutic treatment. Moreover, the enrolled population in these studies is not homogeneous because, as mentioned above, it included patients both with stage III and IV disease.

However, despite these important limitations, the reported data show promising results in terms of safety, reporting a very low rate of severe AEs experienced by the patients. Furthermore, PAI chemotherapy seems to provide important ORRs (see Table 1). As far as life expectancy, it is not possible to express an assessment, as the only phase III study compared the mOS between the two types of treatment, with favorable results.

Therefore, the role of PAI chemotherapy has not been established yet due to the lack of prospective, randomized, controlled, multicentre phase III clinical trials that compare this regional chemotherapy in combination with systemic one to systemic standard chemotherapy or systemic chemotherapy plus radiation therapy. In particular, patients with unresectable locally advanced PC may be more likely to benefit from this treatment with the aim of increasing their resecability rate.

Moreover, this review sheds light on the need to establish proper interventional oncological techniques and methodologies to define the best technical approach to treat the entire pancreatic tumor area.

Ongoing clinical trials might clarify these therapeutic issues. To this regard, our Interventional and Medical Oncology Unit is developing a phase II clinical trial consisting of PAI using modified FOLFIRINOX for patients who are affected by unresectable locally 
advanced PC with the aim of providing patients the most effective therapeutic regimen while also limiting severe systemic toxicity after its intravenous administration.

Author Contributions: Conceptualization, C.L. and G.R.; methodology, C.L.; software, P.M.; validation, G.R. and C.D.G.; formal analysis, C.L.; investigation, C.L. and M.L.; resources, C.L. and M.L.; data curation, C.L. and M.L.; writing-original draft preparation, C.L. and M.L.; writing-review and editing, M.L.; visualization, P.M., C.F. and F.A.; supervision, C.D.G. and G.R.; project administration, C.L., G.R. and C.D.G.; funding acquisition, G.R. and P.M. All authors have read and agreed to the published version of the manuscript.

Funding: This research received no external funding.

Conflicts of Interest: The authors declare no conflict of interest.

\section{References}

1. Ilic, M.; Ilic, I. Epidemiology of pancreatic cancer. World J. Gastroenterol. 2016, 22, 9694-9705. [CrossRef]

2. Ammendola, M.; Currò, G.; Laface, C.; Zuccalà, V.; Memeo, R.; Luposella, F.; Laforgia, M.; Zizzo, N.; Zito, A.; Loisi, D.; et al. Mast Cells Positive for c-Kit Receptor and Tryptase Correlate with Angiogenesis in Cancerous and Adjacent Normal Pancreatic Tissue. Cells 2021, 10, 444. [CrossRef]

3. Ansari, D.; Tingstedt, B.; Andersson, B.; Holmquist, F.; Sturesson, C.; Williamsson, C.; Sasor, A.; Borg, D.; Bauden, M.; Andersson, R. Pancreatic cancer: Yesterday, today and tomorrow. Future Oncol. 2016, 12, 1929-1946. [CrossRef] [PubMed]

4. Tempero, M.A. NCCN Guidelines Updates: Pancreatic Cancer. J. Natl. Compr. Cancer Netw. JNCCN 2019, 17, 603-605. [CrossRef]

5. Conroy, T.; Desseigne, F.; Ychou, M.; Bouché, O.; Guimbaud, R.; Bécouarn, Y.; Adenis, A.; Raoul, J.L.; Gourgou-Bourgade, S.; de la Fouchardière, C.; et al. FOLFIRINOX versus gemcitabine for metastatic pancreatic cancer. N. Engl. J. Med. 2011, 364, 1817-1825. [CrossRef]

6. Golan, T.; Hammel, P.; Reni, M.; Van Cutsem, E.; Macarulla, T.; Hall, M.J.; Park, J.O.; Hochhauser, D.; Arnold, D.; Oh, D.Y.; et al. Maintenance Olaparib for Germline BRCA-Mutated Metastatic Pancreatic Cancer. N. Engl. J. Med. 2019, 381, 317-327. [CrossRef] [PubMed]

7. Goldstein, D.; El-Maraghi, R.H.; Hammel, P.; Heinemann, V.; Kunzmann, V.; Sastre, J.; Scheithauer, W.; Siena, S.; Tabernero, J.; Teixeira, L.; et al. nab-Paclitaxel plus gemcitabine for metastatic pancreatic cancer: Long-term survival from a phase III trial. J. Natl. Cancer Inst. 2015, 107, dju413. [CrossRef]

8. Reni, M.; Zanon, S.; Peretti, U.; Chiaravalli, M.; Barone, D.; Pircher, C.; Balzano, G.; Macchini, M.; Romi, S.; Gritti, E.; et al. Nab-paclitaxel plus gemcitabine with or without capecitabine and cisplatin in metastatic pancreatic adenocarcinoma (PACT-19): A randomised phase 2 trial. Lancet Gastroenterol. Hepatol. 2018, 3, 691-697. [CrossRef]

9. Hahn, S.A.; Schmiegel, W.H. Recent discoveries in cancer genetics of exocrine pancreatic neoplasia. Digestion 1998, 59, $493-501$. [CrossRef]

10. Laforgia, M.; Laface, C. Peripheral Neuropathy under Oncologic Therapies: A Literature Review on Pathogenetic Mechanisms. Int. J. Mol. Sci. 2021, 22, 1980. [CrossRef]

11. Laface, C.; Laforgia, M.; Zito, A.F.; Loisi, D.; Zizzo, N.; Tamma, R.; Gadaleta, C.D.; Porcelli, M.; Currò, G.; Ammendola, M.; et al. Chymase-positive Mast cells correlate with tumor angiogenesis: First report in pancreatic cancer patients. Eur. Rev. Med. Pharmacol. Sci. 2021, 25, 6862-6873. [CrossRef] [PubMed]

12. Zeng, S.; Pöttler, M.; Lan, B.; Grützmann, R.; Pilarsky, C.; Yang, H. Chemoresistance in Pancreatic Cancer. Int. J. Mol. Sci. 2019, 20, 4504. [CrossRef] [PubMed]

13. Ishida, H.; Makino, T.; Kobayashi, M.; Tsuneoka, K. Laparoscopic measurement of pancreatic blood flow. Endoscopy 1983, 15, 107-110. [CrossRef] [PubMed]

14. Ammendola, M.; Gadaleta, C.D.; Frampton, A.E.; Piardi, T.; Memeo, R.; Zuccalà, V.; Luposella, M.; Patruno, R.; Zizzo, N.; Gadaleta, P.; et al. The density of mast cells c-Kit(+) and tryptase $(+)$ correlates with each other and with angiogenesis in pancreatic cancer patients. Oncotarget 2017, 8, 70463-70471. [CrossRef]

15. Ammendola, M.; Sacco, R.; Marech, I.; Sammarco, G.; Zuccalà, V.; Luposella, M.; Patruno, R.; Giordano, M.; Ruggieri, E.; Zizzo, N.; et al. Microvascular density and endothelial area correlate with Ki-67 proliferative index in surgically-treated pancreatic ductal adenocarcinoma patients. Oncol. Lett. 2015, 10, 967-971. [CrossRef] [PubMed]

16. Ammendola, M.; Sacco, R.; Sammarco, G.; Donato, G.; Zuccalà, V.; Luposella, M.; Patruno, R.; Marech, I.; Montemurro, S.; Zizzo, N.; et al. Mast cells density positive to tryptase correlates with angiogenesis in pancreatic ductal adenocarcinoma patients having undergone surgery. Gastroenterol. Res. Pract. 2014, 2014, 951957. [CrossRef]

17. Passantino, L.; Patruno, R.; Valerio, P.; Penna, A.; Mazzone, F.; Zito, A.F.; Catalano, V.; Pellecchia, A.; Jirillo, E.; Ranieri, G. Thymidine phosphorylase profiles in nonmalignant and malignant pancreatic tissue. Potential therapeutic role of capecitabine on tumoral and endothelial cells and tumor-infiltrating macrophages. Immunopharmacol. Immunotoxicol. 2005, 27, 95-107. [CrossRef]

18. Miller, D.W.; Fontain, M.; Kolar, C.; Lawson, T. The expression of multidrug resistance-associated protein (MRP) in pancreatic adenocarcinoma cell lines. Cancer Lett. 1996, 107, 301-306. [CrossRef] 
19. Link, K.H.; Gansauge, F.; Pillasch, J.; Rilinger, N.; Büchler, M.W.; Beger, H.G. Regional Treatment of Advanced Nonresectable and of Resected Pancreatic Cancer via Celiac Axis Infusion. Dig. Surg. 1994, 11, 414-419. [CrossRef]

20. Muchmore, J.H.; Preslan, J.E.; George, W.J. Regional chemotherapy for inoperable pancreatic carcinoma. Cancer 1996, 78, 664-673 [CrossRef]

21. Guadagni, S.; Clementi, M.; Valenti, M.; Fiorentini, G.; Cantore, M.; Kanavos, E.; Caterino, G.P.; Di Giuro, G.; Amicucci, G. Hypoxic abdominal stop-flow perfusion in the treatment of advanced pancreatic cancer: A phase II evaluation/trial. Eur. J. Surg. Oncol. J. Eur. Soc. Surg. Oncol. Br. Assoc. Surg. Oncol. 2007, 33, 72-78. [CrossRef] [PubMed]

22. Cantore, M.; Fiorentini, G.; Bassi, C.; Molani, L.; Aitini, E.; Morandi, C.; Girelli, R.; Amadori, M.; Tumulo, S.; Falconi, M.; et al Intra-Arterial Chemotherapy for Stage-1ll/IV Pancreatic Cancer. Dig. Surg. 1997, 14, 113-118. [CrossRef]

23. Ishikawa, T. Is it relevant that intra-arterial chemotherapy may be effective for advanced pancreatic cancer? World J. Gastroenterol. 2007, 13, 4306-4309. [CrossRef] [PubMed]

24. Laface, C.; Laforgia, M.; Molinari, P.; Ugenti, I.; Gadaleta, C.D.; Porta, C.; Ranieri, G. Hepatic Arterial Infusion of Chemotherapy for Advanced Hepatobiliary Cancers: State of the Art. Cancers 2021, 13, 3091. [CrossRef]

25. Ranieri, G.; Laface, C. Loco-Regional and Systemic Chemotherapies for Hepato-Pancreatic Tumors: Integrated Treatments. Cancers 2020, 12, 2737. [CrossRef]

26. Gadaleta, C.D.; Ranieri, G. Trans-arterial chemoembolization as a therapy for liver tumours: New clinical developments and suggestions for combination with angiogenesis inhibitors. Crit. Rev. Oncol. Hematol. 2011, 80, 40-53. [CrossRef] [PubMed]

27. Ranieri, G.; Laforgia, M.; Nardulli, P.; Ferraiuolo, S.; Molinari, P.; Marech, I.; Gadaleta, C.D. Oxaliplatin-Based Intra-arterial Chemotherapy in Colo-Rectal Cancer Liver Metastases: A Review from Pharmacology to Clinical Application. Cancers 2019, 11, 141. [CrossRef]

28. Gadaleta, C.D.; Solbiati, L.; Mattioli, V.; Rubini, G.; Fazio, V.; Goffredo, V.; Vinciarelli, G.; Gadaleta-Caldarola, G.; Canniello, E.; Armenise, F.; et al. Unresectable lung malignancy: Combination therapy with segmental pulmonary arterial chemoembolization with drug-eluting microspheres and radiofrequency ablation in 17 patients. Radiology 2013, 267, 627-637. [CrossRef]

29. Ranieri, G.; Ammendola, M.; Marech, I.; Laterza, A.; Abbate, I.; Oakley, C.; Vacca, A.; Sacco, R.; Gadaleta, C.D. Vascular endothelial growth factor and tryptase changes after chemoembolization in hepatocarcinoma patients. World J. Gastroenterol. 2015, 21, 6018-6025. [CrossRef]

30. Ranieri, G.; Niccoli Asabella, A.; Altini, C.; Fazio, V.; Caporusso, L.; Marech, I.; Vinciarelli, G.; Macina, F.; de Ceglia, D.; Fanelli, M.; et al. A pilot study employing hepatic intra-arterial irinotecan injection of drug-eluting beads as salvage therapy in liver metastatic colorectal cancer patients without extrahepatic involvement: The first southern Italy experience. OncoTargets Ther. 2016, 9, 7527-7535. [CrossRef]

31. Gadaleta, C.D.; Catino, A.; Ranieri, G.; Armenise, F.; Console, G.; Mattioli, V. Hypoxic stop-flow perfusion with mitomycin-C in the treatment of multifocal liver metastases. Usefulness of a vascular arterial stent to prevent iatrogenic lesions of the hepatic arterial wall. J. Exp. Clin. Cancer Res. CR 2003, 22, 203-206.

32. Ranieri, G.; Marech, I.; Porcelli, M.; Giotta, F.; Palmiotti, G.; Laricchia, G.; Fazio, V.; Gadaleta, C.D. Complete response in a patient with liver metastases from breast cancer employing hepatic arterial infusion 5-fluorouracil based chemotherapy plus systemic nab-paclitaxel. Oncotarget 2018, 9, 8197-8203. [CrossRef]

33. Goffredo, V.; Gadaleta, C.D.; Laterza, A.; Vacca, A.; Ranieri, G. Tryptase serum levels in patients suffering from hepatocellular carcinoma undergoing intra-arterial chemoembolization: Possible predictive role of response to treatment. Mol. Clin. Oncol. 2013, 1, 385-389. [CrossRef]

34. Datta, J.; Narayan, R.R.; Kemeny, N.E.; D’Angelica, M.I. Role of Hepatic Artery Infusion Chemotherapy in Treatment of Initially Unresectable Colorectal Liver Metastases: A Review. JAMA Surg. 2019, 154, 768-776. [CrossRef]

35. Doussot, A.; Kemeny, N.E.; D'Angelica, M.I. Hepatic arterial infusional chemotherapy in the management of colorectal cancer liver metastases. Hepatic Oncol. 2015, 2, 275-290. [CrossRef]

36. Kemeny, N.; Fata, F. Hepatic-arterial chemotherapy. Lancet Oncol. 2001, 2, 418-428. [CrossRef]

37. Yamaue, H.; Tani, M.; Onishi, H.; Kinoshita, H.; Nakamori, M.; Yokoyama, S.; Iwahashi, M.; Uchiyama, K. Locoregional chemotherapy for patients with pancreatic cancer intra-arterial adjuvant chemotherapy after pancreatectomy with portal vein resection. Pancreas 2002, 25, 366-372. [CrossRef] [PubMed]

38. Ibukuro, K. Vascular anatomy of the pancreas and clinical applications. Int. J. Gastrointest. Cancer 2001, 30, 87-104. [CrossRef]

39. Bertelli, E.; Di Gregorio, F.; Mosca, S.; Bastianini, A. The arterial blood supply of the pancreas: A review. V. The dorsal pancreatic artery. Surg. Radiol. Anat. 1998, 20, 445-452. [CrossRef] [PubMed]

40. Covantev, S.; Mazuruc, N.; Belic, O. The Arterial Supply of the Distal Part of the Pancreas. Surg. Res. Pract. 2019, $2019,5804047$. [CrossRef] [PubMed]

41. Tanaka, T.; Sakaguchi, H.; Anai, H.; Yamamoto, K.; Morimoto, K.; Nishiofuku, H.; Kichikawa, K. Catheter position for adequate intra-arterial chemotherapy for advanced pancreatic cancer: Evaluation with CT during arterial injection of contrast material. $J$. Vasc. Interv. Radiol. JVIR 2004, 15, 1089-1097. [CrossRef]

42. Tanaka, T.; Sakaguchi, H.; Anai, H.; Yamamoto, K.; Morimoto, K.; Tamamoto, T.; Kichikawa, K. Arterial infusion of 5-fluorouracil combined with concurrent radiotherapy for unresectable pancreatic cancer: Results from a pilot study. AJR Am. J. Roentgenol. 2007, 189, 421-428. [CrossRef] 
43. Tanaka, T.; Sakaguchi, H.; Sho, M.; Yamamoto, K.; Nishiofuku, H.; Nakajima, Y.; Kichikawa, K. A novel interventional radiology technique for arterial infusion chemotherapy against advanced pancreatic cancer. AJR Am. J. Roentgenol. 2009, 192, W168-W177. [CrossRef] [PubMed]

44. Tanaka, T.; Yamamoto, K.; Sho, M.; Nishiofuku, H.; Inoue, M.; Sueyoshi, S.; Anai, H.; Sakaguchi, H.; Nakajima, Y.; Kichikawa, K. Pharmacokinetic evaluation of pancreatic arterial infusion chemotherapy after unification of the blood supply in an animal model. J. Vasc. Interv. Radiol. JVIR 2010, 21, 116-121. [CrossRef]

45. de Sousa Cavalcante, L.; Monteiro, G. Gemcitabine: Metabolism and molecular mechanisms of action, sensitivity and chemoresistance in pancreatic cancer. Eur. J. Pharmacol. 2014, 741, 8-16. [CrossRef]

46. Spasokoukotskaja, T.; Arnér, E.S.; Brosjö, O.; Gunvén, P.; Juliusson, G.; Liliemark, J.; Eriksson, S. Expression of deoxycytidine kinase and phosphorylation of 2-chlorodeoxyadenosine in human normal and tumour cells and tissues. Eur. J. Cancer 1995, 31A, 202-208. [CrossRef]

47. Van Riel, J.M.; Peters, G.J.; Mammatas, L.H.; Honeywell, R.J.; Laan, A.C.; Ruyter, R.; van den Berg, F.G.; Giaccone, G.; van Groeningen, C.J. A phase I and pharmacokinetic study of gemcitabine given by 24-h hepatic arterial infusion. Eur. J. Cancer 2009, 45, 2519-2527. [CrossRef] [PubMed]

48. Fu, D.; Ni, Q.; Yu, X.; Zhang, Q.; Hua, Y.; Zhang, Y.; Wang, L. Regional intra-arterial infusion chemotherapy for pancreatic cancer: An experimental study. Zhonghua Yi Xue Za Zhi 2002, 82, 371-375.

49. Longley, D.B.; Harkin, D.P.; Johnston, P.G. 5-fluorouracil: Mechanisms of action and clinical strategies. Nat. Rev. Cancer 2003, 3, 330-338. [CrossRef]

50. Tao, W.; Zhao, Y.; Cai, L.; Zhu, Y. Distribution of 5-fluorouracil in plasma and pancreatic tissue of rats during the regional arterial infusion chemotherapy. Zhongguo Yi Xue Ke Xue Yuan Xue Bao 1999, 21, 390-394.

51. Mitsutsuji, M.; Suzuki, Y.; Iwanaga, Y.; Fujino, Y.; Tanioka, Y.; Kamigaki, T.; Ku, Y.; Kuroda, Y. An experimental study on the pharmacokinetics of 5-fluorouracil regional chemotherapy for pancreatic cancer. Ann. Surg. Oncol. 2003, 10, 546-550. [CrossRef]

52. Dzodic, R.; Gomez-Abuin, G.; Rougier, P.; Bonnay, M.; Ardouin, P.; Gouyette, A.; Rixe, O.; Ducreux, M.; Munck, J.N. Pharmacokinetic advantage of intra-arterial hepatic oxaliplatin administration: Comparative results with cisplatin using a rabbit VX2 tumor model. Anti-Cancer Drugs 2004, 15, 647-650. [CrossRef]

53. Kakizaki, K.; Yamauchi, H.; Takahashi, N.; Kikuti, H.; Asamura, M. Long-term arterial infusion chemotherapy in unresectable pancreatic cancer. Gan Kagaku Ryoho. Cancer Chemother. 1989, 16, 2740-2742.

54. Cantore, M.; Pederzoli, P.; Cornalba, G.; Fiorentini, G.; Guadagni, S.; Miserocchi, L.; Frassoldati, A.; Ceravolo, C.; Smerieri, F.; Muchmore, J.H. Intra-arterial chemotherapy for unresectable pancreatic cancer. Ann. Oncol. Off. J. Eur. Soc. Med. Oncol. 2000, 11, 569-573. [CrossRef] [PubMed]

55. Homma, H.; Doi, T.; Mezawa, S.; Takada, K.; Kukitsu, T.; Oku, T.; Akiyama, T.; Kusakabe, T.; Miyanishi, K.; Niitsu, Y. A novel arterial infusion chemotherapy for the treatment of patients with advanced pancreatic carcinoma after vascular supply distribution via superselective embolization. Cancer 2000, 89, 303-313. [CrossRef]

56. Cantore, M.; Fiorentini, G.; Luppi, G.; Rosati, G.; Caudana, R.; Piazza, E.; Comella, G.; Ceravolo, C.; Miserocchi, L.; Mambrini, A.; et al. Gemcitabine versus FLEC regimen given intra-arterially to patients with unresectable pancreatic cancer: A prospective, randomized phase III trial of the Italian Society for Integrated Locoregional Therapy in Oncology. J. Chemother. 2004, 16, 589-594. [CrossRef] [PubMed]

57. Aigner, K.R.; Gailhofer, S. Celiac axis infusion and microembolization for advanced stage III/IV pancreatic cancer-A phase II study on 265 cases. Anticancer Res. 2005, 25, 4407-4412.

58. Mambrini, A.; Sanguinetti, F.; Pacetti, P.; Caudana, R.; Iacono, C.; Guglielmi, A.; Guadagni, S.; Del Freo, A.; Fiorentini, G.; Cantore, M. Intra-arterial infusion of 5-fluorouracil, leucovorin, epirubicin and carboplatin (FLEC regimen) in unresectable pancreatic cancer: Results of a ten-year experience. Vivo 2006, 20, 751-755.

59. Ishikawa, T.; Kamimura, H.; Tsuchiya, A.; Togashi, T.; Watanabe, K.; Seki, K.; Ohta, H.; Yoshida, T.; Takeda, K.; Kamimura, T. Clinical efficacy of intra-arterial pharmacokinetic chemotherapy with 5-fluorouracil, CDDP, gemcitabine, and angiotensin-II in patients with advanced pancreatic cancer. Hepato-Gastroenterol. 2007, 54, 2378-2382.

60. Miyanishi, K.; Ishiwatari, H.; Hayashi, T.; Takahashi, M.; Kawano, Y.; Takada, K.; Ihara, H.; Okuda, T.; Takanashi, K.; Takahashi, S.; et al. A Phase I trial of arterial infusion chemotherapy with gemcitabine and 5-fluorouracil for unresectable advanced pancreatic cancer after vascular supply distribution via superselective embolization. Jpn. J. Clin. Oncol. 2008, 38, 268-274. [CrossRef]

61. Sasada, T.; Denno, R.; Tanaka, T.; Kanai, M.; Mizukami, Y.; Kohno, S.; Takabayashi, A. Intra-arterial infusion chemotherapy with 5-fluorouracil and cisplatin in advanced pancreatic cancer: A feasibility study. Am. J. Clin. Oncol. 2008, 31, 71-78. [CrossRef]

62. Tanaka, T.; Sho, M.; Nishiofuku, H.; Sakaguchi, H.; Inaba, Y.; Nakajima, Y.; Kichikawa, K. Unresectable pancreatic cancer: Arterial embolization to achieve a single blood supply for intraarterial infusion of 5-fluorouracil and full-dose IV gemcitabine. AJR Am. J. Roentgenol. 2012, 198, 1445-1452. [CrossRef]

63. Liu, F.; Tang, Y.; Sun, J.; Yuan, Z.; Li, S.; Sheng, J.; Ren, H.; Hao, J. Regional intra-arterial vs. systemic chemotherapy for advanced pancreatic cancer: A systematic review and meta-analysis of randomized controlled trials. PLoS ONE 2012, 7, e40847. [CrossRef]

64. Chen, Y.; Wang, X.L.; Wang, J.H.; Yan, Z.P.; Cheng, J.M.; Gong, G.Q.; Liu, L.X.; Li, G.P.; Li, C.Y. Transarterial infusion with gemcitabine and oxaliplatin for the treatment of unresectable pancreatic cancer. Anti-Cancer Drugs 2014, 25, 958-963. [CrossRef]

65. Liu, X.; Yang, X.; Zhou, G.; Chen, Y.; Li, C.; Wang, X. Gemcitabine-Based Regional Intra-Arterial Infusion Chemotherapy in Patients With Advanced Pancreatic Adenocarcinoma. Medicine 2016, 95, e3098. [CrossRef] [PubMed] 
66. Qiu, B.; Zhang, X.; Tsauo, J.; Zhao, H.; Gong, T.; Li, J.; Li, X. Transcatheter arterial infusion for pancreatic cancer: A 10-year National Cancer Center experience in 115 patients and literature review. Abdom. Radiol. 2019, 44, 2801-2808. [CrossRef] [PubMed]

67. Ikeda, O.; Kusunoki, S.; Kudoh, K.; Takamori, H.; Tsuji, T.; Kanemitsu, K.; Yamashita, Y. Evaluation of the efficacy of combined continuous arterial infusion and systemic chemotherapy for the treatment of advanced pancreatic carcinoma. Cardiovasc. Interv. Radiol. 2006, 29, 362-370. [CrossRef] [PubMed]

68. Heinrich, S.; Kraft, D.; Staib-Sebler, E.; Schwarz, W.; Gog, C.; Vogl, T.; Lorenz, M. Phase II study on combined intravenous and intra-arterial chemotherapy with gemcitabine and mitomycin $\mathrm{C}$ in patients with advanced pancreatic cancer. Hepato-Gastroenterol. 2013, 60, 1492-1496. [CrossRef]

69. Uwagawa, T.; Misawa, T.; Tsutsui, N.; Ito, R.; Gocho, T.; Hirohara, S.; Sadaoka, S.; Yanaga, K. Phase II study of gemcitabine in combination with regional arterial infusion of nafamostat mesilate for advanced pancreatic cancer. Am. J. Clin. Oncol. 2013, 36, 44-48. [CrossRef]

70. Barletta, E.; Fiore, F.; Daniele, B.; Ottaiano, A.; D’Angelo, R.; Ferrari, E.; Formato, R.; Tortoriello, A.; Turitto, G.; Bruni, G.S.; et al. Second-line intra-arterial chemotherapy in advanced pancreatic adenocarcinoma. Front. Biosci. A J. Virtual Libr. 2006, 11, 782-787. [CrossRef]

71. Suker, M.; Beumer, B.R.; Sadot, E.; Marthey, L.; Faris, J.E.; Mellon, E.A.; El-Rayes, B.F.; Wang-Gillam, A.; Lacy, J.; Hosein, P.J.; et al. FOLFIRINOX for locally advanced pancreatic cancer: A systematic review and patient-level meta-analysis. Lancet Oncol. 2016, 17, 801-810. [CrossRef]

72. Barreto, S.G.; Windsor, J.A. Justifying vein resection with pancreatoduodenectomy. Lancet Oncol. 2016, 17, e118-e124. [CrossRef]

73. Muranaka, T.; Kuwatani, M.; Komatsu, Y.; Sawada, K.; Nakatsumi, H.; Kawamoto, Y.; Yuki, S.; Kubota, Y.; Kubo, K.; Kawahata, S.; et al. Comparison of efficacy and toxicity of FOLFIRINOX and gemcitabine with nab-paclitaxel in unresectable pancreatic cancer. J. Gastrointest. Oncol. 2017, 8, 566-571. [CrossRef] [PubMed] 